Adverse effects are generally limited to those expected of a peripheral vasodilator-flushing and headache and fluid retention; the basis of the recent warning that nifedipine may precipitate angina and even myocardial infarction ${ }^{14}$ is unclear. More recently, nifedipine has been shown to lower blood pressure rapidly, and this effect is prolonged. ${ }^{15}$ The reflex increase in sympathetic activity manifest by a rise in pulse rate and plasma renin concentration suggests that combined treatment with beta-blockade may be appropriate in hypertension.

The problems of treatment with perhexiline have been mentioned in the $B M Y$ before. ${ }^{16}$ The drug is effective, but its adverse effects include peripheral neuropathy, raised intracranial pressure, disturbances of liver function, dizziness, sickness, and ataxia. These preclude its use as an antianginal agent of the first order, though it is a relatively potent calcium antagonist. Prenylamine is also widely used as an antianginal agent, but recent publications have given more emphasis to its propensity to cause arrhythmias ${ }^{17}$ (especially in the presence of hypokalaemia) and heart failure ${ }^{18}$ (especially in patients taking beta-blockers) than to its undoubted therapeutic efficacy.

Where does this leave the clinician? Nitroglycerin remains the drug of choice in angina. Calcium antagonists may yet challenge beta-blockers for second place, especially where the adverse effects of beta-blockade may pose clinical problems, but their final place has not yet been clarified. Some questions remain to be answered. Do these drugs have the potential to limit the size of a myocardial infarct? When used as antihypertensive agents, might they prevent death from myocardial infarction, which conventional antihypertensive treatment (including beta-blockers) has so far not been shown to do ? The answer to these and other problems must await further clinical experience.

1 Cranefield PF. The conduction of the cardiac impulse. The slow response and cardiac arrhythmias. New York: Futura Publishing Co, 1975.

${ }^{2}$ Huxley AF. The activation of striated muscle and its mechanical response. Proceedings of the Royal Society; Series B 1971;178:1-27.

${ }^{3}$ Ebashi S, Endo M. Calcium ion and muscle contraction. Prog Biophys Mol Biol 1968;18:123-83.

4 Andersson KE. Effects of calcium and calcium antagonists on excitationcontraction coupling in striated and smooth muscle. Acta Pharmacol Toxicol (Kbh) $1979 ; 43$, suppl 1:5-14.

5 Fleckenstein A. Specific inhibitors and promoters of calcium action in the excitation-contraction coupling of heart muscle and their role in the prevention or production of myocardial lesions. In: Harris $\mathbf{P}$, Opie $\mathbf{L}$, eds. Calcium and the heart. New York: Academic Press, 1971 :135-88.

${ }^{6}$ Krikler D. Verapamil in cardiology. Eur $\mathcal{f}$ Cardiol 1974;2:3-10.

7 Singh BN, Ellrodt G, Peter CT. Verapamil, a review of its pharmacological properties and therapeutic use. Drugs 1978;15:169-97.

${ }^{8}$ Zelis RF, Schroeder JS. Calcium, calcium antagonists and cardiovascular disease. Chest 1980;78, suppl:121-247.

- Endo M, Kanda I, Hosoda S, Hayashi H, Hirosawa K, Konno S. Prinzmetal's variant form of angina pectoris. Re-evaluation of mechanisms. Circulation 1975;52:33-7.

10 de Ponti C, Mauri F, Ciliberto GR, Carie B. Comparative effects of nifedipine, verapamil, isosorbide dinitrate and propranolol on exerciseinduced angina pectoris. Eur $\mathcal{f}$ Cardiol 1979;10:47-58.

11 Ekelund LG, Orö L. Antianginal efficiency of nifedipine with and without a beta-blocker, studied with exercise test. A double-blind, randomized subacute study. Clinical Cardiology 1979;2:203-11.

12 Lynch P, Dargie H, Krikler S, Krikler D. Objective assessment of antianginal treatment: a double-blind comparison of propranolol, nifedipine, and their combination. $B r M e d \mathcal{f} 1980 ; 281: 184-7$.

13 Anastassiades CJ. Nifedipine and beta-blocker drugs. Br Med $\mathcal{F} 1980 ; 281$ : 1251-2.

14 Committee on Safety of Medicines. Current problems, No 4. April 1979.

15 Guazzi MD, Fiorentini C, Olivari MT, Bartorelli A, Necchi G, Polese A. Short- and long-term efficacy of a calcium-antagonistic agent (nifedipine) combined with methyldopa in the treatment of severe hypertension. Circulation $1980 ; 61$ :913-9.

16 Anonymous. Drug treatment of chronic stable angina pectoris. $\mathrm{Br} \mathrm{Med} \mathcal{F}$ $1978 ; \mathrm{i}: 462-3$.

${ }^{17}$ Puritz R, Henderson MA, Baker SN, Chamberlain DA. Ventricular arrhythmias caused by prenylamine. $B r$ Med f 1977;ii:608-9.

18 Opie LH. Calcium antagonists. Lancet 1980;i:806-9.

\section{Occupational physicians and ethics}

Earlier this year the BMA published The Occupational Physician, ${ }^{1}$ a development of its long-familiar pamphlet "The Doctor in Industry." As a practical guide to the whole- or part-time doctor in occupational medicine it should prove as valuable as its predecessor. In particular, the booklet contains a useful appendix on ethics, a subject that the Faculty of Occupational Medicine of the Royal College of Physicians has also tackled in its Guidance on Ethics for Occupational Physicians. ${ }^{2}$ Both publications make it clear that the ethical aspects of occupational medicine can be complex, calling for some delicate professional judgments by the doctors concerned. The Faculty points out that occupational physicians practise in a subject where major changes are taking place in the relation between medicine and those parts of society represented in industry. Ethical behaviour is defined as a duty self-imposed on each doctor; the incentive is his need for the approval of colleagues rather than the avoidance of official censure.

The place of the doctor in any business concern should be that of an independent professional adviser who has the confidence of both management and employees. The guidelines look at some specific aspects. The question of certificates of fitness to work is dealt with at length. Problems may arise because a bald statement about the fitness or otherwise of the person for a specific job may not give sufficient information. In these circumstances the guiding principle must be that clinical details can be disclosed only with the informed agreement of the individual employee. The only exception is the rare case when the safety of other workers or of the general public is threatened, when duty to the public overrides the principle of confidentiality.

In assessing whether an individual is fit or unfit for a job, the occupational physician has to assess that individual's working capacity in relation to the physical or mental requirements of the job. The interests of the individual and the employer should be given equal emphasis. The question of acceptability for admission to a pension scheme is not relevant so far as the employability of an individual is concerned; if a candidate is fit for the job he must be fit for the pension scheme.

Another problem specific to occupational physicians is that of dealing with commercial confidence, such as the details of manufacturing processes or procedures. The potential effects on the health of employees of any materials handled must be discussed openly with the workers, and the information must be made available to the medical staff of other companies whose workers may be required to handle the products or byproducts.

During the routine and periodic examinations of workers required by statute occupational physicians need to recognise that the circumstances in which individuals attend for examination are fundamentally different from those of the normal doctor-patient relationship. At these examinations the doctor needs to make sure that he confines himself to relevant questions or procedures in order to retain the confidence of the patient.

Between them, the two publications also give consideration to records and screening and to the all-important relations with other doctors. In addition, relations with management, trades unions, government agencies, and other professionals working in occupational health and safety, such as nurses, 
safety officers, occupational hygienists, and administrative officers, are covered.

The profession's concern with the ethics of occupational health practice has been stimulated by the recent increase in the number of doctors practising occupational medicine and the establishment of procedures for the formal training of doctors entering the specialty. The legislation concerned with the wellbeing of persons at work, which culminated in the Health and Safety at Work Act 1974, has, indeed, transferred occupational medicine from the study of industrial diseases to the care of workers in every sort of occupation. The collective guidance from the BMA and the faculty will help strengthen the foundation for the growth and development of this expanding discipline.

\footnotetext{
${ }^{1}$ British Medical Association. The Occupational Physician. London: British Medical Association, 1980.

${ }^{2}$ Faculty of Occupational Medicine. Guidance on Ethics for Occupational

Physicians. London: Royal College of Physicians of London, 1980.
}

\section{Aspirin and the stomach}

The gastrointestinal side effects of acetylsalicylic acid affect a substantial minority of those taking the drug. Between $2 \%$ and $6 \%$ of patients will have dyspepsia, nausea, and vomiting, ${ }^{1-3}$ while the loss of blood in the stools may be 10-20 times greater than normal, depending on the dose. ${ }^{45}$ Endoscopic studies have shown that mucosal damage may occur in all persons given aspirin immediately before the procedure. ${ }^{6-8}$ Long-term ingestion of aspirin may damage the mucosa both in normal individuals ${ }^{910}$ and in patients with rheumatic disease. ${ }^{11}$ Nevertheless, epidemiological evidence suggests that only persons who take aspirin regularly (on four or more days a week) or in large doses (more than 15 tablets a week) are likely to suffer acute gastrointestinal bleeding or gastric ulceration. ${ }^{12}$ These serious consequences are, indeed, rare: their respective incidences are only 15 and 10 per 100000 habitual aspirin users. There may, therefore, be some justification for the belief that the adverse effects of aspirin have been overemphasised. ${ }^{1314}$ Even so, in practical terms the issue is still important, for several reasons. Firstly, the average annual consumption of aspirin in Britain is between 3500 million and 6000 million tablets, or one and a half to two tablets weekly per person $^{1516}$; secondly, life-threatening acute gastrointestinal haemorrhage may occur in any individual patient after taking aspirin; and, thirdly, some patients, such as those with rheumatoid arthritis, may need to take high doses of aspirin for a prolonged period.

Given that aspirin will continue to be used (and it clearly will) and that there is a risk (though small) of serious gastrointestinal adverse effects, then an attempt should be made to combine optimum effect with minimal risk in choosing which of the many aspirin or aspirin-containing preparations to use in an individual patient. Clearly aspirin should not be prescribed for patients with disease of the upper gastrointestinal tract. Excluding these, there are two general circumstances in which aspirin is likely to be used. The first is the treatment of minor, transient complaints-toothache, headache, and influenza-when a rapid analgesic and sometimes an antipyretic effect is required and the treatment is expected to be brief. In contrast, in rheumatic disorders, particularly rheumatoid arthritis, high dosage is required to achieve an anti-inflammatory effect, but speed of onset is less important.

The choice of preparations for short, rapid action is among standard, soluble, and buffered aspirin. Taken on an empty stomach standard aspirin is rapidly absorbed at a rate which depends on the formulation-faster with small particle size. ${ }^{17}$ Coarse particles may lodge in the mucosa and cause congested, haemorrhagic areas. ${ }^{18}$ The occult loss of blood is proportionate to the dose. ${ }^{4}$ Soluble aspirin (a combination of aspirin, calcium carbonate, and citric acid) is absorbed more rapidly than standard aspirin and produces about half as much occult bleeding ${ }^{49}$ and is therefore to be preferred-though occult bleeding may not be correlated with gastric side effects. Theoretically buffered aspirin preparations should raise gastric $\mathrm{pH}$, speed up gastric emptying, and be less likely to produce gastric erosions, ${ }^{8}$ though these may be absorbed more slowly. In practice, however, many of these compounds contain insufficient buffer to be effective ${ }^{20}$ : one exception is effervescent buffered aspirin, which contains sodium bicarbonate and is so highly buffered that long-term use might result in alkalosis. ${ }^{1721}$ Enteric-coated or slow-release preparations are not suitable for treatment requiring a rapid effect.

For maintenance dosage swift onset of action is less important than the ability to give dosage without substantial adverse gastric effect. Preparations designed for intestinal rather than gastric release may be preferred, provided that effective release and absorption of the drug can be shown. ${ }^{22}$ Recently, the effects of prolonged administration of various aspirin preparations have been compared in an endoscopic study in normal volunteers. ${ }^{1020}$ Enteric-coated aspirin was shown to be much less likely to produce gastric or duodenal injury than standard or buffered aspirin at comparable concentrations of salicylate in the serum. A support for these findings was given by a report on 82 patients with rheumatic disease taking aspirin for at least three months ${ }^{11}$ : gastric ulcers were found in about a quarter of those taking conventional aspirin but in less than one in ten of those taking entericcoated tablets.

Information on the many preparations of aspirin is not full enough to allow definitive choices. Present knowledge suggests that soluble aspirin should be used for occasional or intermittent needs when a rapid effect is required but that enteric-coated aspirin appears to offer advantages for high-dose maintenance treatment, provided that the formulation is satisfactory.

1 Muir A, Cossar IA. Aspirin and ulcer. Br Med f 1955;ii:7-12.

2 Miller RR, Jick $H$. Acute toxicity of aspirin in hospitalized medical patients. Am f Med Sci 1977;274:271-9.

${ }^{3}$ Benson JA. Gastrointestinal reactions to drugs. Am $\mathcal{F}$ Dig Dis 1971 ;16: 357-62.

${ }^{4}$ Pierson RN Jr, Holt PR, Watson RM, Keating RP. Aspirin and gastrointestinal bleeding. Chromate ${ }^{51}$ blood loss studies. Am $\mathcal{F}$ Med $1961 ; 31$ 259-65.

5 Wood PH. Salicylates. Bull Rheum Dis 1963;13:297-300.

6 Weiss A, Pitman ER, Graham EC. Aspirin and gastric bleeding. Gastroscopic observations, with review of literature. $A m \mathcal{F} M e d 1961$;31:266-78.

7 Vickers FN, Stanley MM. Aspirin gastritis. Gastroduodenoscopic observations. Gastroenterology 1963;44:419-23.

8 Thorsen WB, Western D, Tanka T, Morrisey JF. Aspirin injury to the gastric mucosa. Gastrocamera observations on the effect of pH. Arch Intern Med 1968:121:499-506.

${ }^{9}$ Metzger WH, McAdam L, Bluestone R, Guth PH. Acute gastric mucosal injury during continuous or interrupted aspirin ingestion in humans. Am F Dig Dis 1976;21:963-8.

${ }^{10}$ Hoftiezer JW, Silvoso GR, Burks M, Ivey KJ. Comparison of the effects of regular and enteric-coated aspirin on gastroduodenal mucosa of man. Lancet 1980;ii:609-12.

11 Silvoso GR, Ivey KJ, Butt JH, et al. Incidence of gastric lesions in patients with rheumatic disease on chronic aspirin therapy. Ann Intern Med 1979; 91 :517-20. 